\title{
The Prognosis and Recovery of Aphasia Related to Stroke Lesion
}

\author{
Bomi Sul, MD, Joon Sung Kim, MD, PhD, Bo Young Hong, MD, PhD, Kyoung Bo Lee, PT, PhD, \\ Woo Seop Hwang, SLP, Young Kook Kim, MD, Seong Hoon Lim, MD, PhD
}

Department of Rehabilitation Medicine, St. Vincent Hospital, College of Medicine, The Catholic University of Korea, Suwon, Korea

\begin{abstract}
Objective To investigate the effects of specific brain lesions on prognosis and recovery of post-stroke aphasia, and to assess the characteristic pattern of recovery.

Methods Total of 15 subjects with first-ever, left hemisphere stroke, who were right handed, and who completed language assessment using the Korean version of the Western Aphasia Battery (K-WAB) at least twice during the subacute and chronic stages of stroke, were included. The brain lesions of the participants were evaluated using MRIcron, SPM8, and Talairach Daemon software.

Results Subtraction of the lesion overlap map of the participants who showed more than $30 \%$ improvement in the aphasia quotient (AQ) by the time of their chronic stage $(n=9)$ from the lesion overlap map of those who did not show more than $30 \%$ improvement in the AQ $(n=6)$ revealed a strong relationship with Broca's area, inferior prefrontal gyrus, premotor cortex, and a less strong relationship with Wernicke's area and superior and middle temporal gyri. The culprit lesion related to poor prognosis, after grouping the subjects according to their AQ score in the chronic stage (a cut score of 50), revealed a strong relationship with Broca's area, superior temporal gyrus, and a less strong relationship with Wernicke's area, prefrontal cortex, and inferior frontal gyrus.

Conclusion Brain lesions in the Broca's area, inferior prefrontal gyrus, and premotor cortex may be related to slow recovery of aphasia in patients with left hemisphere stroke. Furthermore, involvement of Broca's area and superior temporal gyrus may be associated with poor prognosis of post-stroke aphasia.
\end{abstract}

Keywords Stroke, Aphasia, Prognosis, Recovery

\section{INTRODUCTION}

Aphasia is one of the most common post-stroke disabil- ities [1], and its incidence following first-ever stroke had been reported to be $30 \%-38 \%$ in hospitalized patients [2]. Traditionally, several areas of the brain are known to be

Received November 6, 2015; Accepted March 7, 2016

Corresponding author: Seong Hoon Lim

Department of Rehabilitation Medicine, St. Vincent Hospital, College of Medicine, The Catholic University of Korea, 93 Jungbu-daero, Paldal-gu, Suwon 16247, Korea. Tel: +82-31-249-7650, Fax: +82-31-251-4481, E-mail: seonghoon@catholic.ac.kr

ORCID: Bomi Sul (http://orcid.org/0000-0001-7166-8997); Joon Sung Kim (http://orcid.org/0000-0001-7457-593X); Bo Young Hong (http://orcid. org/0000-0001-9290-6173); Kyoung Bo Lee (http://orcid.org/0000-0002-7652-1393); Woo Seop Hwang (http://orcid.org/0000-0002-7644-2003); Young Kook Kim (http://orcid.org/0000-0003-3964-026X); Seong Hoon Lim (http://orcid.org/0000-0002-5475-4153).

(c) This is an open-access article distributed under the terms of the Creative Commons Attribution Non-Commercial License (http://creativecommons.org/ licenses/by-nc/4.0) which permits unrestricted noncommercial use, distribution, and reproduction in any medium, provided the original work is properly cited. Copyright (C) 2016 by Korean Academy of Rehabilitation Medicine 
responsible for language, such as Broca's and Wernicke's areas, and the transcortical and subcortical pathways which connect them [3]. However, lesions in other areas can also manifest features of aphasia, and many studies have been investigating the further brain lesions related to language network $[4,5]$. Advances in neuroimaging such as voxelwise lesion-behavior mapping (VLBM) and diffusion tensor imaging (DTI) have allowed us to locate these lesions [6,7], and these insights might be helpful in understanding the effects of the lesions; thus, enabling greater accuracy of clinical diagnosis and better management.

The aim of this study is to investigate the effect of the specific brain lesion site on prognosis and recovery of aphasia, along with assessment of the characteristic recovery pattern of subacute and chronic post-stroke aphasia.

\section{MATERIALS AND METHODS}

\section{Study design and participants}

This is a retrospective study of patients with aphasia resulting from acute stroke, who were admitted to the Department of Rehabilitation Medicine of St. Vincent's Hospital from January 2009 to December 2014. The inclusion criteria were as follows: (1) first-ever stroke, (2) only one left hemisphere lesion, either ischemic or hemorrhagic, confirmed by magnetic resonance imaging (MRI), (3) right handedness, and (4) completion of language assessment using the Korean version of the Western Aphasia Battery (K-WAB) at least twice, first assessment within 3 months post-onset of stroke and the other assessment(s) at least 3 months after the initial assessment. No restriction was placed on the type or severity of the aphasia, and subjects were excluded if they had any other functional or structural brain disorder. Of the 372 individuals, only 15 qualified for the study.

All subjects were investigated with respect to their demographic data and the results of their language assessments were collected. For precise localization of their brain lesions, high resolution 1.5T anatomical MRI scans with a 5-mm slice thickness were analyzed using MRIcron, SPM8, and Talairach Daemon software [8].

The study was approved by the Ethics Committee of The Catholic University of Korea.

\section{Language test}

All participants were examined using the validated K$\mathrm{WAB}$, and the results were subjected to analysis only when aphasia was caused by first-ever stroke at the time of admission.

The WAB assessment is composed of four subtests of fluency, comprehension, repetition, and naming. The severity of aphasia is quantified using aphasia quotient (AQ; range, 0-100), which was calculated using the Kertesz's formula [9]: (fluency score+comprehension score/20 + repetition score $/ 10+$ naming score $/ 10) \times 2$.

Subjects included in the study completed their initial WAB assessment within 3 months of stroke onset, and the follow-up test was completed at least 3 months after the initial assessment. Changes in AQ and the four subsets of WAB were compared and evaluated to determine their significance.

\section{Lesion tracing and analysis procedures}

Lesion size was calculated using the Picture Achieved Communication System (PACS; Marotech, Seoul, Korea), and the absolute lesion size $\left(\mathrm{cm}^{3}\right)$ was determined by multiplying the sum of all lesion areas in each plane by the slice thickness.

Localization of the brain lesions was conducted using MRIcron. The origin of the image $(0,0,0 \mathrm{~mm}$ coordinates) was reoriented to locate as close as possible to the anterior commissure. VOI images of each patient were traced using MRIcron software (http://www.mricro.com/ mricron), and then the tracings were coregistered to the Montreal Neurological Institute brain templates [10]. In order to deduce the lesion overlap maps, the first step is to roughly align the $\mathrm{Tl}$ image onto a standard space. This will approximately locate the anterior commissure, which will aid subsequent normalization. The next step is to coregister the $\mathrm{T} 2$ scan to the space of the $\mathrm{T} 1$ scan. The T2 image will then be moved and rotated until it is closely aligned with the $\mathrm{T} 1 \mathrm{scan}$. The final step is to align the T1 image in the stereotaxic space. This series of processes was performed in combination with SPM8 unified segmentation and normalization. The Talairach Daemon software (http://www.talairach.org) was used to identify relevant anatomic structures implicated in the analysis [11]. 


\section{Statistical analysis}

Statistical analysis was performed using the SPSS software ver. 20.0 (IBM, Armonk, NY, USA). All continuous variables were analyzed with non-parametric testing using Mann-Whitney test, due to non-normal distribution. All tests were two-tailed, and statistical significance was accepted for $\mathrm{p}$-values $<0.05$.

\section{RESULTS}

A total of 15 patients were included in the study. Among them, there were 7 males and 8 females, with an average age of $55.27 \pm 18.07$ years, ranging from 22 to 80 years.
Patients underwent their initial K-WAB at a mean time period of 38.8 \pm 21.24 days (range, 15-90 days) after the onset of stroke, and the follow-up K-WAB at a mean time period of $185.8 \pm 69.70$ days (range, 109-313 days) after the onset of stroke (Table 1). The average interval between the initial and the subsequent K-WAB assessments was 147.0 \pm 56.10 days (range, 94-257 days). The follow-up KWAB results showed statistically significant improvement in three of the four subtests of K-WAB, including fluency, comprehension, and repetition. The most prominent improvement was noted in the comprehension aspect (Table 2).

The lesion overlap map for all 15 participants showed extensive coverage over the left hemisphere supplied by

Table 1. Baseline characteristics and brain lesions of the subjects

\begin{tabular}{|c|c|c|c|c|c|c|c|c|}
\hline $\begin{array}{l}\text { Patient } \\
\text { no. }\end{array}$ & Sex/age & Brain lesion & $\begin{array}{l}\text { Lesion } \\
\text { volume } \\
\left(\mathrm{cm}^{3}\right)\end{array}$ & $\begin{array}{c}\text { Initial } \\
\text { K-WAB } \\
\text { test date } \\
\text { after onset } \\
\text { (day) }\end{array}$ & $\begin{array}{c}\text { Initial } \\
\text { K-WAB } \\
\text { AQ }\end{array}$ & $\begin{array}{c}\text { Follow-up } \\
\text { K-WAB } \\
\text { test date } \\
\text { after the } \\
\text { onset (day) }\end{array}$ & $\begin{array}{c}\text { Follow-up } \\
\text { K-WAB } \\
\text { AQ }\end{array}$ & $\begin{array}{l}\text { Aphasia } \\
\text { type }\end{array}$ \\
\hline 1 & $\mathrm{M} / 64$ & $\begin{array}{l}\text { Infarction, posterior } \\
\text { branch of the MCA, } \\
\text { left }\end{array}$ & 27.53 & 46 & 13.2 & 303 & 21.4 & Wernicke's \\
\hline 2 & $\mathrm{M} / 22$ & ICH, frontal lobe, left & 47.73 & 22 & 20.4 & 121 & 72.6 & Broca's \\
\hline 3 & $\mathrm{~F} / 65$ & $\mathrm{ICH}$, frontal lobe, left & 33.57 & 53 & 57.6 & 220 & 82.5 & $\begin{array}{l}\text { Transcortical } \\
\text { motor }\end{array}$ \\
\hline 4 & $\mathrm{M} / 54$ & ICH, temporal lobe, left & 18.37 & 42 & 12.4 & 169 & 17.7 & Global \\
\hline 5 & $\mathrm{M} / 43$ & ICH, putamen, left & 29.53 & 90 & 62.0 & 266 & 71.8 & $\begin{array}{l}\text { Transcortical } \\
\text { motor }\end{array}$ \\
\hline 6 & $\mathrm{~F} / 80$ & $\begin{array}{l}\text { ICH, basal ganglia } \\
\text { and thalamus, left }\end{array}$ & 71.36 & 23 & 0 & 125 & 7.1 & Global \\
\hline 7 & $\mathrm{M} / 74$ & ICH, basal ganglia, left & 12.22 & 33 & 2.3 & 130 & 56.9 & Global \\
\hline 8 & $\mathrm{M} / 62$ & $\begin{array}{l}\text { Infarction, frontal, } \\
\text { temporal, and } \\
\text { parietal lobes, left }\end{array}$ & 105.06 & 21 & 0 & 179 & 5.7 & Global \\
\hline 9 & $\mathrm{~F} / 34$ & $\begin{array}{l}\text { Infarction, } \\
\text { MCA territory, left }\end{array}$ & 2.67 & 71 & 18.8 & 313 & 29.7 & Broca's \\
\hline 10 & $\mathrm{~F} / 24$ & ICH, basal ganglia, left & 24.46 & 37 & 76.6 & 142 & 90.4 & Anomic \\
\hline 11 & $\mathrm{M} / 64$ & $\begin{array}{l}\text { Infarction, } \\
\text { MCA territory, left }\end{array}$ & 4.88 & 21 & 32.9 & 122 & 30.3 & $\begin{array}{l}\text { Mixed } \\
\text { transcortical }\end{array}$ \\
\hline 12 & $\mathrm{~F} / 74$ & $\begin{array}{l}\text { Infarction, frontal lobe } \\
\text { including insula, left }\end{array}$ & 34.74 & 21 & 0 & 146 & 0.6 & Global \\
\hline 13 & $\mathrm{~F} / 69$ & ICH, basal ganglia, left & 24.92 & 15 & 4.1 & 109 & 59.6 & Global \\
\hline 14 & $\mathrm{~F} / 46$ & ICH, basal ganglia, left & 40.71 & 55 & 10.5 & 181 & 36.4 & Global \\
\hline 15 & $\mathrm{~F} / 54$ & $\begin{array}{l}\text { ICH, frontal and } \\
\text { temporal lobes, left }\end{array}$ & 37.30 & 32 & 25.4 & 261 & 27.5 & Wernicke's \\
\hline
\end{tabular}

K-WAB, Korean version of the Western Aphasia Battery; AQ, aphasia quotient; MCA, middle cerebral artery; ICH, intracerebral hemorrhage. 
The Prognosis and Recovery of Aphasia Related to Stroke Lesion

Table 2. Results of the language evaluations (K-WAB)

\begin{tabular}{lccc}
\hline & Initial K-WAB & Follow-up K-WAB & p-value $^{\text {a) }}$ \\
\hline Aphasia quotient & $13.20(0.00-76.60)$ & $30.30(0.6-90.40)$ & 0.056 \\
Fluency & $3.00(0.00-13.00)$ & $8.50(0.00-17.50)$ & 0.045 \\
Comprehension & $45.00(0.00-155.00)$ & $111.00(6.00-194.00)$ & 0.009 \\
Repetition & $0.00(0.00-82.00)$ & $50.00(0.00-100.00)$ & 0.023 \\
Naming & $0.00(0.00-57.00)$ & $16.00(0.00-98.00)$ & 0.074 \\
\hline
\end{tabular}

Values are given in median (range).

Maximum scores: aphasia quotient out of 100; fluency, 20; comprehension, 200; repetition, 100; and naming, 100. $\mathrm{K}-\mathrm{WAB}$, Korean version of the Western Aphasia Battery.

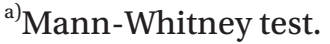

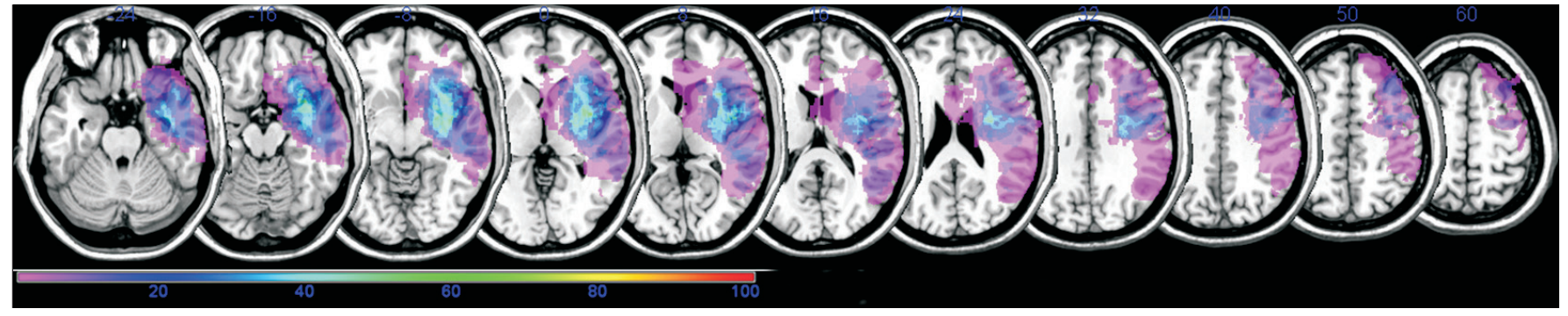

Fig. 1. Lesion overlap map for all participants $(n=15)$. Color spectrum based on overlapping proportion (\%).

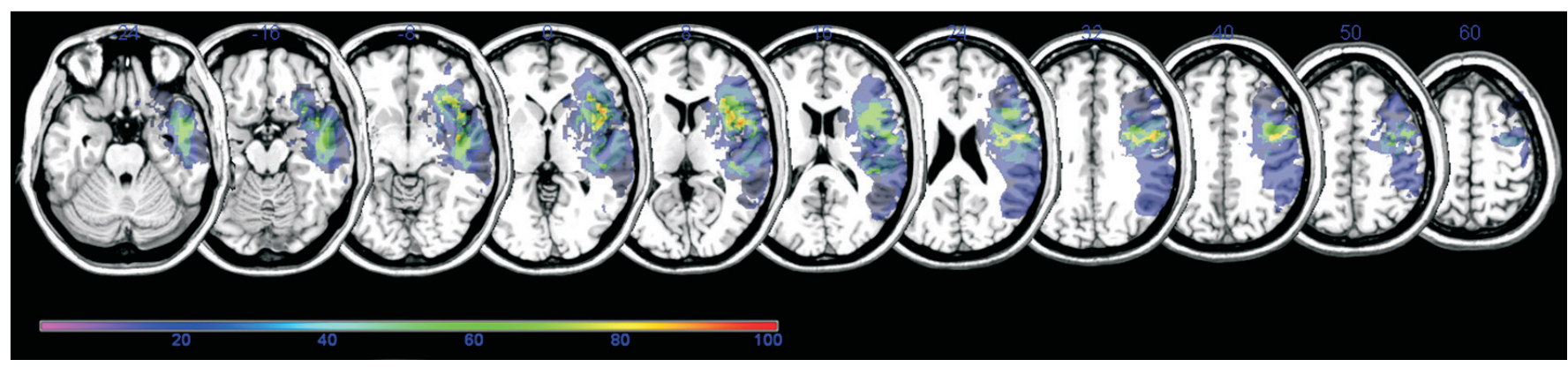

Fig. 2. Subtraction of overlay of participants with more than $30 \%$ AQ improvement $(n=9)$ from that of those with less than $30 \%$ AQ improvement $(n=6)$. Color spectrum based on overlapping proportion (\%). AQ, aphasia quotient.

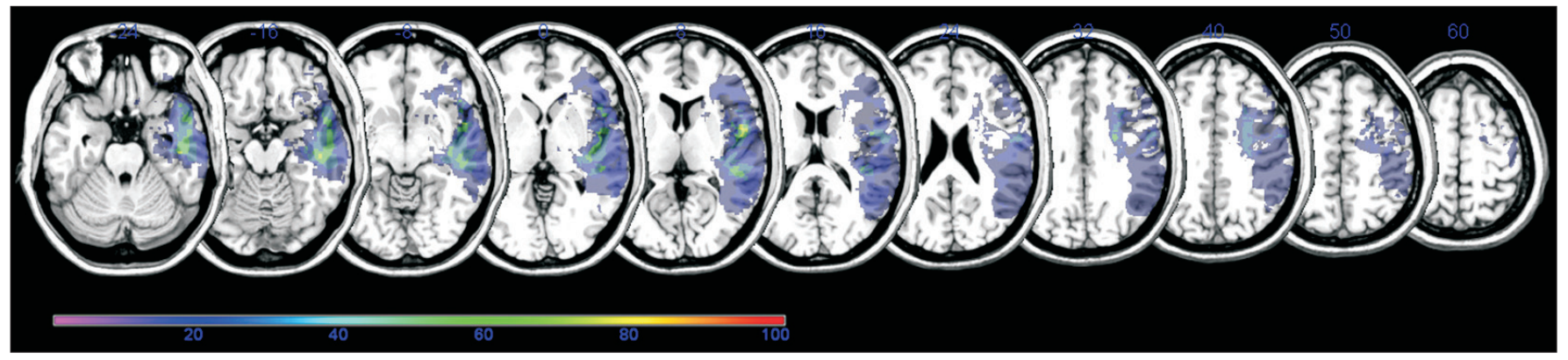

Fig. 3. Subtraction of overlay of participants with follow-up AQ more than $50(n=6)$ from that of those with follow-up AQ less than $50(n=9)$. Color spectrum based on overlapping proportion (\%). AQ, aphasia quotient. 
the middle cerebral artery (Fig. 1). The colors represent the frequency of overlapping.

Participants who showed more than $30 \%$ improvement in AQ by the time of the follow-up K-WAB (n=9) and those who did not show more than $30 \%$ improvement in AQ $(n=6)$ were separated (Table 3$)$. There was no significant difference in age and brain lesion volume categories between the two groups $(\mathrm{p}=0.328$ and $\mathrm{p}=0.181$, respectively). Subtraction of the lesion overlap map of the pre- vious group from that of the latter group revealed a strong relationship with Broca's area, inferior prefrontal gyrus, and premotor cortex, and a less strong relationship with Wernicke's area and superior and middle temporal gyri in the left hemisphere (Fig. 2).

Then, the participants whose AQ in the follow-up KWAB was equal to or higher than $50(n=6)$ and those whose AQ in the follow-up K-WAB was less than $50(n=9)$ were separated (Table 4). There was no significant differ-

Table 3. Group characteristics depending on the improvement in AQ

\begin{tabular}{|c|c|c|c|}
\hline & $\geq 30 \%$ improvement in AQ $(n=9)$ & $<30 \%$ improvement in AQ $(n=6)$ & p-value ${ }^{\text {a) }}$ \\
\hline \multicolumn{4}{|l|}{ Sex } \\
\hline Male & 4 & 3 & \\
\hline Female & 5 & 3 & \\
\hline Age (yr) & $50.22 \pm 19.70$ & $62.83 \pm 13.36$ & 0.328 \\
\hline Brain lesion volume $\left(\mathrm{cm}^{3}\right)$ & $25.80 \pm 13.89$ & $47.15 \pm 35.46$ & 0.181 \\
\hline \multicolumn{4}{|l|}{ Aphasia type } \\
\hline Anomic & 1 & 0 & \\
\hline Broca's & 2 & 0 & \\
\hline Global & 4 & 3 & \\
\hline Mixed transcortical & 0 & 1 & \\
\hline Transcortical motor & 1 & 1 & \\
\hline Wernicke's & 1 & 1 & \\
\hline
\end{tabular}

Values are presented as number or mean \pm standard deviation.

$\mathrm{AQ}$, aphasia quotient.

${ }^{a)}$ Mann-Whitney test.

Table 4. Group characteristics depending on the follow-up AQ

\begin{tabular}{|lccc}
\hline & $\mathbf{A Q} \geq \mathbf{5 0}(\mathbf{n}=\mathbf{6})$ & $\mathbf{A Q}<\mathbf{5 0}(\mathbf{n}=\mathbf{9})$ & $\mathbf{p}$-value $\mathbf{v}^{\text {a) }}$ \\
\hline Sex & & & \\
\hline Male & 3 & 5 & \\
\hline Female & 3 & $59.11 \pm 14.00$ & 0.607 \\
\hline Age (yr) & $49.50 \pm 23.11$ & $38.07 \pm 32.54$ & 0.689 \\
\hline Brain lesion volume $\left(\mathrm{cm}^{3}\right)$ & $28.73 \pm 11.75$ & & \\
\hline Aphasia type & & 0 & \\
\hline Anomic & 1 & 1 & \\
\hline Broca's & 1 & 5 & \\
\hline Global & 2 & 0 & \\
\hline Mixed transcortical & 0 & 2 \\
\hline Transcortical motor & 2 & 0 & \\
\hline Wernicke's & 0 & & \\
\hline
\end{tabular}

Values are presented as number or mean \pm standard deviation.

$\mathrm{AQ}$, aphasia quotient.

${ }^{a)}$ Mann-Whitney test. 
ence in age and brain lesion volume categories between the two groups ( $\mathrm{p}=0.607$ and $\mathrm{p}=0.689$, respectively). Subtraction of the lesion overlap map of the previous group from that of the latter group revealed a strong relationship with Broca's area and superior temporal gyrus, and a less strong relationship with Wernicke's area, prefrontal cortex, and inferior frontal gyrus in the left hemisphere (Fig. 3).

\section{DISCUSSION}

Our results indicate that involvement of Broca's area, the motor center of speech, and superior temporal gyrus, the comprehension center, is related to poor long-term outcome of aphasia in left hemisphere stroke [12]. Meanwhile, involvement of inferior prefrontal gyrus, which plays an important role in semantic processing [13,14], and premotor cortex, which is associated with apraxia of speech, may not determine the prognosis of aphasia, but impedes recovery of aphasia [15]. Also, Broca's area is not only associated with poor prognosis, but also with rate or recovery of aphasia. Clinically, treatment with a focus on recovering semantic language or improving apraxia of speech can be attempted for optimal recovery in aphasic patients with damage to the inferior prefrontal gyrus or premotor cortex. Further studies involving such treatment modalities are promising, and they may be helpful in understanding the interrelationship between longterm outcome and recovery rate or pattern of aphasia.

Recent studies have revealed that impairment in many other brain sites beyond the classical Broca's or Wernicke's areas may be closely related to aphasia [16]. With respect to the role of premotor cortex in the language pathway, many recent studies have reported the involvement of motor areas in speech perception [17]. Left premotor cortex is involved in transforming perceived sounds into motor representations, with aid of bilateral superior temporal cortex [17]. In addition, in rhesus, the ventrolateral prefrontal cortex is thought to be part of a circuit involved in representing vocalizations and other auditory objects [18]. In the study by Eickhoff et al. [19], the final output of speech production is sent to the premotor cortex, and it converts movement patterns into muscle-specific commands. Furthermore, studies using perfusion-weighted imaging, structural MRI analysis, and functional imaging with FDG-PET have shown that damage or hypoperfusion in the inferior frontal gyrus and lateral premotor cortex strongly predicts apraxia of speech [20].

However, improved neuroimaging methods and analysis prove that both functional and structural connectivity within the speech network differ in persons [20]. Since aphasia is a multi-dimensional disorder in which patient profiles reflect variation along multiple behaviors, it may be mandatory to approach aphasia under multiple core factors such as phonology, semantics, and cognition [6]. With the use of principle components analysis and voxelbased lesion-symptom mapping (VLSM), Butler et al. [6] proved that the phonological aspect of post-stroke aphasia was uniquely correlated with damage to the left mid to posterior superior temporal gyrus, middle temporal gyrus, superior temporal sulcus, Heschl's gyrus, and arcuate fasciculus component of the dorsal language route. Furthermore, the semantic aspect of aphasia was uniquely related to the left anterior middle temporal gyrus, and the ventral language route.

In our study, only 12 of the 15 participants had been tested for cognitive function using the Mini-Mental State Examination (MMSE) within the first 2 months after the onset of stroke, and follow-up MMSE scores had been recorded after this period in only 7 of these patients. Due to the small number of participants and incomplete data, we were unable to draw a conclusion on the relationship between post-stroke aphasia and cognitive function. Nonetheless, it is well-known that cognitive impairment often co-exists with aphasia in post-stroke patients, limiting the efficacy of rehabilitation of language. According to Lee and Pyun [21], attention and working memory ability were significantly worse in aphasic patients, and another study showed the severity of aphasia was significantly correlated with them [22]. In addition, spoken communication is susceptible to orientation, spatial perception, and visual perception, which are also strongly connected with improvement from aphasia, especially in naming and comprehension functions [23].

Several previous studies noted that not only the location, but also the size of the brain lesion plays a role in determining the prognosis of aphasia in stroke patients $[24,25]$. However, in our study, there was no significant difference in the volume of brain lesions between the groups (Tables 3, 4). Other studies have reported that the location of the brain lesion is more crucial than the ex- 
tent or size of the lesion [26]. Among them, many studies attest that the recovery of aphasia is inversely related to the size; thus, reinforcing the importance of preservation of the left superior temporal gyrus and basal ganglia [27].

With respect to interval change of language function, the follow-up K-WAB results in the subacute or chronic stage of stroke showed statistically significant improvement in three of the four subtests of K-WAB, including fluency, comprehension, and repetition. The most prominent improvement was noted in the comprehension aspect. Smania et al. [28] reported a case in which the authors studied the long-term outcome of language in a patient with global aphasia after a large ischemic lesion in the left middle cerebral artery territory. Several tests including the Milan Language Examination, the Token Test, the Raven Test, and tests for apraxia were repeated, and the patient's first year after stroke was characterized by recovery of verbal comprehension and word repetition, the next 2 years were characterized by emergence of naming and reading, and the next 20 years were characterized by a progressive improvement in the above areas and emergence of spontaneous speech. The rate of improvement estimated at 1 year was the highest in the comprehension aspect (70\%), followed by the repetition aspect (50\%). Krishnan et al. [29] studied 12 first-ever hemorrhagic stroke-aphasic subjects, and all participants with non-global aphasia showed preserved comprehension skills. Those with initial global aphasia exhibited recovery of comprehension skills, thus evolving to Broca's aphasia at the follow-up evaluation. In their study, the comprehension skills of the subjects were relatively spared, and when affected, they showed faster recovery when compared to the other aspects.

The main limitation of our study was the small number of patients. Recovery pattern of aphasia may also be affected by the type of aphasia; however, our study has a small sample size to investigate this aspect. Further studies involving larger number of subjects are warranted. In addition, other factors which may influence language function such as the cognitive or psychological aspect of the patients should be evaluated in more depth. Last, but not the least, assessment of not only the affected or impaired lesions, but also the structural or functional connectivity between the lesions may be of great importance, probably by incorporating functional MRI or DTI.

According to our findings, involvement of Broca's area, inferior prefrontal gyrus, and premotor cortex might be related to the slow recovery rate of aphasia in left hemisphere stroke. Furthermore, involvement of Broca's area and superior temporal gyrus might be related to poor long-term outcome of aphasia in left hemisphere stroke. These results could be useful for planning aphasia rehabilitation and for further understanding the prognosis of post-stroke aphasia.

\section{CONFLICT OF INTEREST}

No potential conflict of interest relevant to this article was reported.

\section{REFERENCES}

1. Hoffmann M, Chen R. The spectrum of aphasia subtypes and etiology in subacute stroke. J Stroke Cerebrovasc Dis 2013;22:1385-92.

2. Berthier ML, Pulvermuller F, Davila G, Casares NG, Gutierrez A. Drug therapy of post-stroke aphasia: a review of current evidence. Neuropsychol Rev 2011; 21:302-17.

3. Charidimou A, Kasselimis D, Varkanitsa M, Selai C, Potagas C, Evdokimidis I. Why is it difficult to predict language impairment and outcome in patients with aphasia after stroke? J Clin Neurol 2014;10:75-83.

4. Cappa SF. The neural basis of aphasia rehabilitation: evidence from neuroimaging and neurostimulation. Neuropsychol Rehabil 2011;21:742-54.

5. Crinion J, Holland AL, Copland DA, Thompson CK, Hillis AE. Neuroimaging in aphasia treatment research: quantifying brain lesions after stroke. Neuroimage 2013;73:208-14.

6. Butler RA, Lambon Ralph MA, Woollams AM. Capturing multidimensionality in stroke aphasia: mapping principal behavioural components to neural structures. Brain 2014;137(Pt 12):3248-66.

7. Saur D, Hartwigsen G. Neurobiology of language recovery after stroke: lessons from neuroimaging studies. Arch Phys Med Rehabil 2012;93(1 Suppl):S15-25.

8. Lee KB, Kim JS, Hong BY, Kim YD, Hwang BY, Lim $\mathrm{SH}$. The motor recovery related with brain lesion in patients with intracranial hemorrhage. Behav Neurol 2015;2015:258161.

9. Kertesz A, Poole E. The aphasia quotient: the taxo- 
nomic approach to measurement of aphasic disability. Can J Neurol Sci 1974;1:7-16.

10. Brett M, Leff AP, Rorden C, Ashburner J. Spatial normalization of brain images with focal lesions using cost function masking. Neuroimage 2001;14:486-500.

11. Lancaster JL, Woldorff MG, Parsons LM, Liotti M, Freitas CS, Rainey L, et al. Automated Talairach atlas labels for functional brain mapping. Hum Brain Mapp 2000;10:120-31.

12. Friederici AD, Ruschemeyer SA, Hahne A, Fiebach CJ. The role of left inferior frontal and superior temporal cortex in sentence comprehension: localizing syntactic and semantic processes. Cereb Cortex 2003;13:170-7.

13. Gabrieli JD, Poldrack RA, Desmond JE. The role of left prefrontal cortex in language and memory. Proc Natl Acad Sci U S A 1998;95:906-13.

14. Poldrack RA, Wagner AD, Prull MW, Desmond JE, Glover GH, Gabrieli JD. Functional specialization for semantic and phonological processing in the left inferior prefrontal cortex. Neuroimage 1999;10:15-35.

15. Itabashi R, Nishio Y, Kataoka Y, Yazawa Y, Furui E, Matsuda M, et al. Damage to the left precentral gyrus is associated with apraxia of speech in acute stroke. Stroke 2016;47:31-6.

16. Blank I, Balewski Z, Mahowald K, Fedorenko E. Syntactic processing is distributed across the language system. Neuroimage 2016;127:307-23.

17. Meister IG, Wilson SM, Deblieck C, Wu AD, Iacoboni $M$. The essential role of premotor cortex in speech perception. Curr Biol 2007;17:1692-6.

18. Cohen YE, Theunissen F, Russ BE, Gill P. Acoustic features of rhesus vocalizations and their representation in the ventrolateral prefrontal cortex. J Neurophysiol 2007;97:1470-84.

19. Eickhoff SB, Heim S, Zilles K, Amunts K. A systems perspective on the effective connectivity of overt speech production. Philos Trans A Math Phys Eng Sci 2009; 367:2399-421.

20. Ballard KJ, Tourville JA, Robin DA. Behavioral, computational, and neuroimaging studies of acquired apraxia of speech. Front Hum Neurosci 2014;8:892.

21. Lee B, Pyun SB. Characteristics of cognitive impairment in patients with post-stroke aphasia. Ann Rehabil Med 2014;38:759-65.

22. Seniow J, Litwin M, Lesniak M. The relationship between non-linguistic cognitive deficits and language recovery in patients with aphasia. J Neurol Sci 2009; 283:91-4.

23. Yu ZZ, Jiang SJ, Bi S, Li J, Lei D, Sun LL. Relationship between linguistic functions and cognitive functions in a clinical study of Chinese patients with post-stroke aphasia. Chin Med J (Engl) 2013;126:1252-6.

24. Kertesz A, Harlock W, Coates R. Computer tomographic localization, lesion size, and prognosis in aphasia and nonverbal impairment. Brain Lang 1979; 8:34-50.

25. Mazzocchi F, Vignolo LA. Localisation of lesions in aphasia: clinical-CT scan correlations in stroke patients. Cortex 1979;15:627-53.

26. Watila MM, Balarabe SA. Factors predicting poststroke aphasia recovery. J Neurol Sci 2015;352:12-8.

27. Heiss WD, Thiel A, Kessler J, Herholz K. Disturbance and recovery of language function: correlates in PET activation studies. Neuroimage 2003;20 Suppl 1:S42-9.

28. Smania N, Gandolfi M, Aglioti SM, Girardi P, Fiaschi A, Girardi F. How long is the recovery of global aphasia? Twenty-five years of follow-up in a patient with left hemisphere stroke. Neurorehabil Neural Repair 2010;24:871-5.

29. Krishnan G, Tiwari S, Pai AR, Rao SN. Variability in aphasia following subcortical hemorrhagic lesion. Ann Neurosci 2012;19:158-60. 